\section{An Analysis of A Teacher's Questioning Related to Students' Responses and Mathematical Creativity in An Elementary School in The UK} Mela Aziza

\begin{tabular}{ll}
\hline Received: & 14 February 2018 \\
Revised: $\quad 20$ March 2018 \\
Accepted: $\quad 20$ March 2018 \\
ISSN: 1307-9298 \\
Copyright @ IEJEE \\
www.iejee.com
\end{tabular}

DOI: 10.26822/iejee.2018438138

\begin{abstract}
Questioning has an important role in teaching mathematics. There is current research about questioning, especially related to class discussion and students' responses. Some researchers suggest teachers pose any kind of questions in mathematics classroom regarding problem solving and mathematical creativity. This research focused on a teacher's questioning activity and students' responses as well as students' mathematical creativity in response to the teacher's questions. This study used observation of a lesson that involved a teacher and twenty-seven third-year students (aged 7-8). Audio recording and notes were taken during the observation, and six students' work samples were also collected. The researcher transcribed the audio and then formulated appropriate interview questions for the teacher and six students chosen. The interview was conducted for clarifying the observation done and analysing what students' mathematical creativity looked like. This interview was also recorded and transcribed. The teacher applied some questioning techniques like using PowerPoint and a wait-time technique asking different questions both closed and open-ended questions. When asked questions, students were able to produce different responses. However, students gave longer answers to open-ended questions especially while the teacher asked questions "How?" and "Why?". The results also showed that open-ended questions could stimulate students' mathematical creativity.
\end{abstract}

Keywords: Questioning activity, students' responses, mathematical creativity, closed questions, open-ended questions

\section{Introduction}

Questioning has a significant role in teaching and learning activities included in a mathematics classroom. The majority of mathematics teachers are likely to spend $60 \%$ of their lesson asking questions (Sullivan \& Lilburn, 2002). Martino and Maher (1999) stated that some studies found that teachers' questioning affected the growth of students' conceptual knowledge that helped the advancement of students' mathematical thinking. Questioning can also help teachers for some points: to investigate whether the students were listening and understand the lesson; to stimulate students' thinking; to develop communication between students and teachers; and to help students achieve educational objectives (Shahrill, 2013). Furthermore, Boaler and Brodie (2004) explained that a teacher's questioning plays a role in controlling classroom environments and creating the flow of classroom discussion. These roles identified the importance of teachers' questioning in the classroom. It seemed that the previous studies were conducted to figure out the interaction between teachers and students, but there are still few areas to research about questioning and classroom discussion (Muir, 2009). Therefore, a study regarding to teachers' questions that stimulate a rich discussion is still required to be analysed further.

Capraro et al. (2007) think that it is necessary to provide students with numerous problem-solving experiences that include both closed- and open-ended problems. However, some studies found that most of the questions that teachers provided in teaching and learning mathematics were closed questions that had only one correct answer (Muir, 2009; Kwon et al., 2006). Teachers are required to pose different kinds of questions in order to stimulate mathematical creativity as one of standards of a mathematics curriculum (Kwon et al., 2006). Kwon et al. (2006) believe that mathematics education should emphasise mathematical creativity to give an opportunity for students to develop multiple solutions when answering a question. Although creativity is pivotal in teaching and learning mathematics, it is still questionable what kind of students' creativity in the classroom (Silver, 1997). Hence, it is still become an issue that can be studied.

Because of this background, I intend to find out the answers for two research questions in this study: how a teacher asked questions to students? and what mathematical creativity looked like from students' responses to the questions in the mathematics classroom?

\section{Theoretical Framework}

\section{Teachers'questioning}

Teachers have to consider how they should ask questions to students, encouraging students to share their answers (Cotton, 2001). Teachers can also ask either oral or written questions to individuals or groups. Cotton suggested that teachers do a wait-time technique after asking a question in which teachers provide time for students to consider about the question before answering because occasionally students are not able to respond to questions spontaneously.

\section{The type of questions}

Although Boaler and Brodie (2004) classified teachers' questions into nine categories based on teachers' goals and questioning techniques, they will be hard to use for analysis because some categories have a similar meaning. Meanwhile, Yee (2002) divided the type of questions regarding the number of possible correct answers, into two types of questions, closed- and open-ended questions. Closed-ended questions have only one correct answer while open-ended questions have multiple answers. 


\section{Students' responses}

Muir (2009) classified students' responses into explanation, sharing, justification, challenge and answer/response. Explanation is different to sharing because students are required to explain their answer or strategy. Justification refers to when students elaborate their explanation, usually occurring when responding to a probing question. The challenge category is given by students while they question or challenge the answer. Meanwhile, if students give a brief answer or response, this response would be termed the answer/response category.

\section{Mathematical creativity}

Silver (1997) described three parts of mathematical creativity: fluency (the number of different answers); flexibility (the number of strategies to solve the question); and originality (how rare the response in the set of all responses or the infrequency of the response). Kwon et al. (2006) found that open-ended questions were effective in fostering students' mathematical creativity because these questions allowed students to apply their own strategy in finding diverse answers that were likely to be novel.

\section{Methodology}

This study involved a female teacher who teaches mathematics for third-year children (aged 7-8) in primary school as well as a whole class of year three that consisted of twenty-seven students. Data was collected using observation and interviews. The observation was done in one lesson that involved a whole class for investigating the way the teacher asked questions, the type of questions that the teacher posed and the responses that students gave. During the observation, a whole-class activity between the teacher and students was recorded, notes were also taken, and six students' work samples were collected randomly. The audio was transcribed, and then the researcher set up appropriate interview questions based on the purpose of the study and the issues that were found in the observation and then required clarification. The interview process engaged the teacher and six students individually for clarifying the observation done and analysing what students' mathematical creativity looked like. This interview was also recorded and transcribed.

In this qualitative research, there is found an issue related to the validity and reliability of the recording data. Therefore, the researcher ensured that the data was valid by applied "appropriateness of the tools, processes, and data" (Leung, 2015; p. 328) in this study through a lesson observation. The researcher was also not involved in the teaching and learning process in which it could prevent biased interpretations during data collection process. Furthermore, previous researchers (Chin, 2007; Franke et al., 2009; Martin \& Hand, 2009; Muir, 2009) used the similar method, observations, for investigating teachers' questioning activity though they have different research aims. Meanwhile, related to reliability, Leung (2015) stated that researchers have to ensure a consistency of their research process and findings. During collecting data the researcher applied the same approach using voice recording and then transcribing it by rewinding the recorder some times. Thus, I assumed this study will be valid and reliable.

\section{Results}

\section{The observation of one lesson}

During the lesson, the teacher taught about numbers and angles. This is a short extract from the transcript showing the teacher's questioning about numbers and students' responses to the questions.

Table 1. Teacher's questioning activity

\begin{tabular}{|c|c|c|}
\hline Time & Questioning activity & \\
\hline $11: 12: 40$ & $\begin{array}{c}\text { Teacher: If the answer is } 42 \text { what } \\
\text { could the question be? You can use } \\
\text { one add, one takeaway, one times, } \\
\text { one divide }\end{array}$ & $\begin{array}{l}\text { Open, } \\
\text { Problem } \\
\text { posing }\end{array}$ \\
\hline 11:15:19 & Cleo: 40 add 2 equals 42 & Answer 1 \\
\hline 11:15:23 & Teacher: Is it correct? & Checking \\
\hline 11:15:36 & Joe: 62 take away 20 equals 42 & Answer 2 \\
\hline 11:15:53 & Amell: 59 take away 7 equals 42 & Answer 3 \\
\hline 11:16:03 & $\begin{array}{l}\text { Emily: } 4 \text { times } 10 \text { add } 2 \text {. Put bracket } \\
\text { for } 4 \text { and } 10\end{array}$ & Answer 4 \\
\hline 11:16:14 & Teacher: Well done & Praising \\
\hline 11:16:19 & Joe: 32 add 10 & Answer 5 \\
\hline 11:16:30 & Sienna: 8 times 4 & \\
\hline 11:16:32 & $\begin{array}{c}\text { Teacher: Can you tell me what } 8 \times 4 \\
\text { is? }\end{array}$ & \multirow{2}{*}{$\begin{array}{l}\text { Additional } \\
\text { Question }\end{array}$} \\
\hline 11:16:40 & Teacher: Rovie? & \\
\hline 11:16:41 & Rovie: 32 , then $+10=42$ & Answer 6 \\
\hline 11:16:46 & Teacher: Good, Obsa? & Praising \\
\hline 11:16:53 & Obsa: $42+0$ & Answer 7 \\
\hline $11: 16: 54$ & $\begin{array}{c}\text { Teacher: Wow, } 42 \text { add nothing } \\
\text { equals } 42\end{array}$ & Originality \\
\hline 11:17:00 & Tom: $6 \times 7$ & Answer 8 \\
\hline 11:17:03 & $\begin{array}{c}\text { Teacher: } O K, 6 \times 7=42 . \text { What's the } \\
\text { opposite/the inverse } 6 \times 7 ?\end{array}$ & $\begin{array}{l}\text { Additional } \\
\text { question }\end{array}$ \\
\hline $11: 17: 20$ & Cloe: $7 \times 6$ & \\
\hline 11:17:31 & Brian: 42 divided by 1 & Answer 9 \\
\hline $11: 17: 34$ & $\begin{array}{c}\text { Teacher: Oh, I like it, so, if } 42 \text { divides } \\
\text { to one person= } 42\end{array}$ & $\begin{array}{c}\text { Originality } \\
\text { Praising }\end{array}$ \\
\hline 11:17:47 & Sienna: $84: 2=42$ & Answer 10 \\
\hline
\end{tabular}

Then, in the last part of the lesson, the teacher gave a task that consisted of some questions that were shown by a slide on PowerPoint (see Figure1). The teacher instructed students to draw three different triangles then answer some questions about these triangles. Students might write their answers in their exercise books. The teacher did not check students' answers due to the limited time.

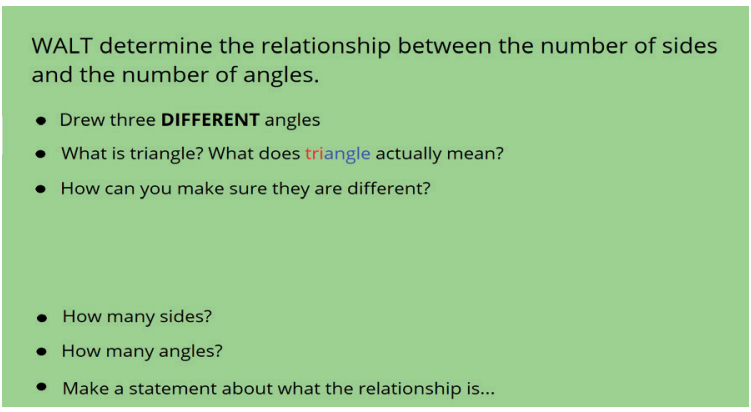

Figure 1. A task on the slide

The researcher collected six students' exercise books to look how the students answered the questions, and then found six different answers below;

\section{The interview of the teacher and six students}

The interview with the teacher looked further into the teacher's questioning that was observed before. Individu 

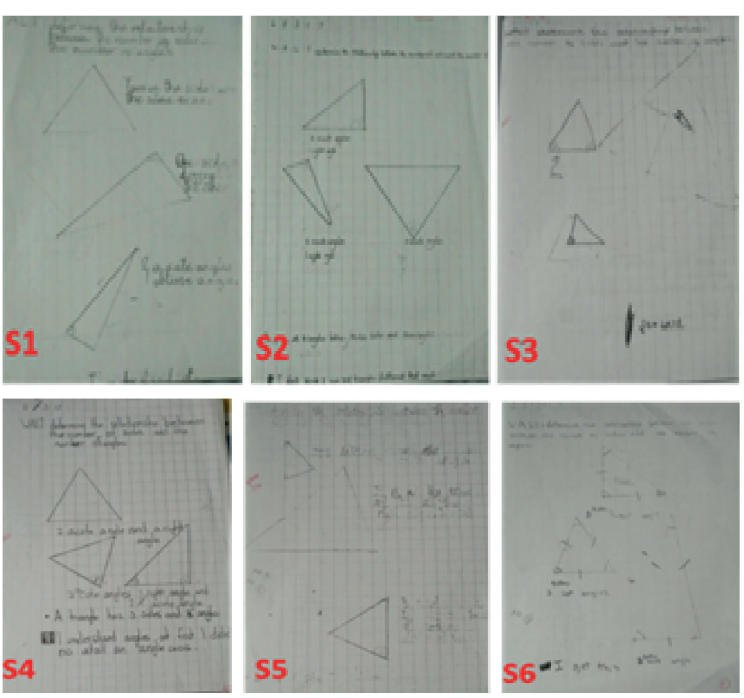

Figure 2. Different triangles drawn by six students

al interviews with the six students for clarifying what they had done were also carried out. From the interview, the teacher stated that she applied two questioning methods, asking students orally and giving students written tasks:

Teacher: Both, if I am doing teaching input orally maybe the questions come orally... I think you don't need to have a worksheet every single lesson so it just comes from me, while another day, they might have a list of questions about clocks.

In addition, when asked about the type of questions that she used, the teacher gave the answer below:

Teacher: Sometimes, it depends on the subjects. If you want yes or no answers, you use closed. If you want a deeper un derstanding, you use open-ended because they can make students think and come up with different ideas, and extend the learning. So, I like to think I do both. More open especially in maths because you want to see links between concepts rather than think just enough.

When asked what she thought about the correctness of the student's answer, the teacher said she believed there was no incorrect answer.

Teacher: I don't believe there is an incorrect answer. I be lieve there are just misconceptions. So, I would work with the child's response and try, by asking them further questions, to make them realise about their mistakes and get to the right answer. Good questions allow for mistakes and you build more questions from that.

Furthermore, when asking students about why they thought the three triangles that they drew were different. Four of them assumed they were different because of their sizes:

Student 1: It's bigger, this one is smaller and this is thin

Meanwhile, others looked from the angles that those triangles had:

Student 2: I'm not quite sure because two are quite similar. They have the same angles and this one is different.

The students were also asked to draw as many different angles as they could to further investigate students' understanding of angles. Surprisingly, the students gave the answers below in which they drew triangles instead of angles:
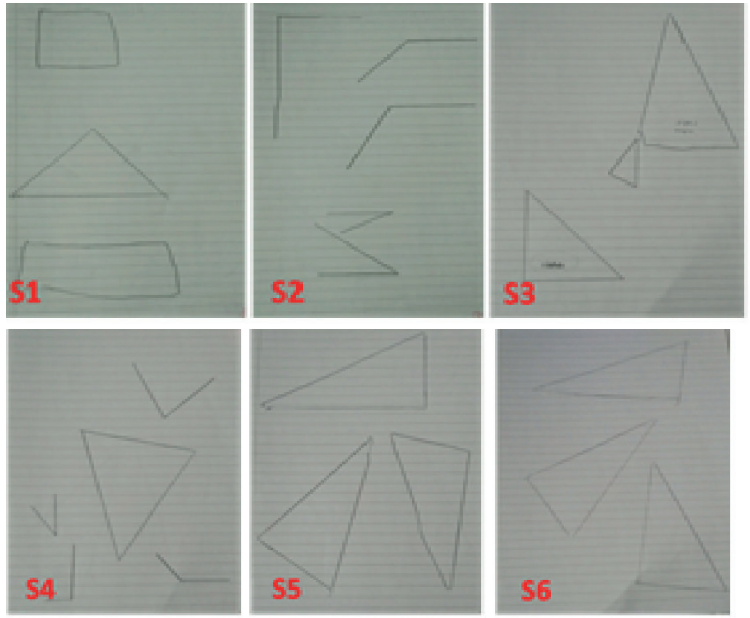

Figure 3. Different angles drawn

\section{Teacher's questioning}

The teacher asked different types of questions using different techniques, posing most questions orally. She also used slides on PowerPoint for illustrating the questions (see Figure 1), asking students to write down the answers in their exercise books. Hence, the teacher posed both oral and written questions. It seems from the gap of time between the teacher's questions and students' answers (see Table 1), the teacher did the wait-time technique, waiting for students' responses. She also spontaneously developed additional questions based on students' answers to explore students' ideas further and involved the whole class to check the answer. Through this process, the students could share their ideas with each other and investigated whether the answer was correct or not. In addition, in another topic, angles, the teacher not only posed questions to an individual but also instructed students to discuss in pairs for answering the question (see teacher's instruction in Table 2 below).

\section{The type of questions}

There were forty-eight questions that the teacher posed during a lesson, ten questions about numbers and the rest of them about angles. Twenty-six questions are closed, and the others are open questions. The teacher asked some different expressions in asking either closed or open-ended questions (see Table 2 below):

Table 2. Some different questions asked

\begin{tabular}{cc}
\hline Closed questions & Open-ended questions \\
\hline Can you tell me what $8 \times 4$ is? & $\begin{array}{c}\text { If the answer is } 42 \text { what could } \\
\text { the question be? Where does } \\
\text { it come from? }\end{array}$ \\
\hline $\begin{array}{c}\text { What's the opposite/the } \\
\text { inverse } 6 \times 7 ?\end{array}$ & $\begin{array}{c}\text { Show me an angle with your } \\
\text { body? }\end{array}$ \\
\hline What's double two? & Why? Explain to your partner! \\
\hline $\begin{array}{c}\text { What is this (red)? What's } \\
\text { rectangle has? Is that straight } \\
\text { line? }\end{array}$ & $\begin{array}{c}\text { With your partner, discuss } \\
\text { 3 statements about these } \\
\text { pictures! }\end{array}$ \\
\hline $\begin{array}{c}\text { Does it have an angle? What's } \\
\text { triangle? Does the length of } \\
\text { the side influence angle? }\end{array}$ & How can you make sure they \\
are different?
\end{tabular}


Thus, it is seen that the teacher asked both closed and open-ended questions during a lesson. In the interview, the teacher stated that she asked the question based on the subject and what she wanted students to have gained. She would ask closed questions when asking "yes or no answers". However, she would ask open questions if she intended to encourage students to think deeply and to link mathematical conceptions with multiple ideas. When ask ing closed questions, the teacher tried to push students to analyse what she meant by the question, for example, when the teacher asked about "inverse" that boosted students to think about the meaning of inverse, and then they tried to answer the question (see Table 1). Furthermore, the teacher posed students a problem that was one of the types of open-ended questions, an open-ended problem posing (Yee, 2002), in which the teacher asked students to create their own questions based on the statement that she provided. From this open-ended problem posing teachers successfully raised different answers from students (see Table 1). The teacher also encouraged students to analyse the errors of their classmates' answers by asking, "Is it correct?" so that students learned to investigate the correctness of the answer. Moreover, the teacher developed students' communication and reasoning skills by asking, "Where does it come from?", "How?" and "Why?".

\section{Students' responses}

There are multiple answers orally that students gave during the lesson. These answers are more than the number of questions that the teacher asked because some open-ended questions produced multiple responses/answers from students (see Table 1). From analysing the transcript of the whole observation, students gave answers that were categorised into fifteen explanations, three justifications and forty-seven brief answers/responses. Students would mostly explain the reason behind their answers when facing the questions, "Why" and "How" (see Table 2) and gave short answers when the teacher asked "yes or no questions" that belong to closed questions. Meanwhile, the teacher's instruction to create statements based on the question could encourage students' justifications.

\section{Open-ended questions produced students' mathematical cre- ativity}

Students' mathematical creativity related to fluency, flexibility, and originality can be seen from students' answers to open-ended questions. For instance, from an open-ended question in Table 1, there are ten different answers (fluency) that students gave from which the teacher praised three of the responses (originality). Mostly students answered with one basic operation, however, one student posed a question using two basic operations (flexibility). In addition, the six students' answers (see Figure 2) for a task (see Figure 1) showed multiple triangles (fluency). For mathematical ideas (flexibility), most children assumed their three triangles were different by considering the size of the triangle (smaller, bigger, and thin). Meanwhile, two other children thought that their triangles were different because of the angles of the triangles. However, they encountered confusion because two of their triangles had a similar type of angles so that they assumed these two triangles were quite similar. The originality of those six students' answers could not be determined because the researcher did not have enough comparison answers to all students in the classroom. Although the six students were asked directly to draw different possible angles in the interview, the majority of students answered by drawing triangles not angles (see Figure 3). Two of the students also had quite similar answers.

\section{Discussion}

The teacher in this study spent most of a lesson by asking questions orally. Whether it is better for students still cannot be looked at directly because she surely had goals and reasons why she did it. She was seen trying to do effective questioning for a lesson by posing closed and open-ended questions. Closed questions make students answer either correctly or incorrectly because those questions have an exact answer. However, teachers do not use open-ended questions just to check the correctness of the answer, but to focus more on developing students' communication, mathematical ideas, reasoning, and problem-solving skills (Kwon et al., 2006). Therefore, both correct and incorrect answers are important for teachers. This study found that the teacher did not look for the correctness of the students' answers during the lesson. However, this teacher's thought has to be investigated further in the future because the teacher may be concerned with the correctness of answers in different lessons based on her teaching goals. Furthermore, open-ended questions seem to foster students' mathematical creativity (Kwon et al., 2006), but to evaluate students' mathematical creativity, teachers may face difficulties especially looking for the originality of students' ideas. The category of an original idea may be different for different teachers because of their personal experience and judgment of the idea. Open-ended questions that encourage students to produce multiple answers will also challenge teachers to think quickly what they should do to respond to unexpected answers. Occasionally, teachers also need to give additional questions to boost students to think further about their answers, especially when they have misconceptions about the questions. This happened during interviews when students had misconceptions between angles and triangles (see Figure 3). The reason why this happened may be caused by students' misunderstandings about the definition of angle or the researcher's pronunciation between "three angles" and "triangles". This pronunciation was likely to be confusing for students because the interviewer is not a native speaker.

\section{Conclusion}

Every teacher seems to have his/her own considerations in posing questions so that what the teacher has done in this research may be different to other teachers. Teachers determine the type of questions that they want to ask based on their teaching goals for students' gain. From this research, it also seems that open-ended questions can be used by a teacher not only for producing mathematical creativity but also developing additional questions to stimulate students' thinking and analysing further students' misunderstandings.

\section{Acknowledgements}

I am really grateful to my sponsorship, Indonesia Endowment Fund for Education (LPDP), that gave me a great opportunity to continue my master degree in this university. I also thank LPDP because they support the fund for my conference.

\section{References}

Boaler, J., \& Brodie, K. (2004, October). The importance, nature, and impact of teacher questions. In Proceedings of the twenty-sixth annual meeting of the North American Chapter of the International Group for the Psychology of Mathematics Education (Vol. 2, pp. 774-790). Toronto, Canada: PMENA. 
Capraro, M. M., Capraro, R. M., \& Cifarelli, V. V. (2007). What are students thinking as they solve open-ended mathematics problems?. In Proceedings of the ninth international conference of Mathematics Education in a Global Community. Charlotte: North Carolina.

Chin, C. (2007). Teacher questioning in science classrooms: Approaches that stimulate productive thinking. Journal of Research in Science Teaching, 44(6), 815843.

Cotton, K. (2001). Classroom questioning. School improvement research series, 3. Retrieved from http://www. learner.org/workshops/socialstudies/pdf/session6/6.ClassroomQuestioning.pdf

Franke, M. L., Webb, N. M., Chan, A. G., Ing, M., Freund, D., \& Battey, D. (2009). Teacher questioning to elicit students' mathematical thinking in elementary school classrooms. Journal of Teacher Education, 60(4), 380-392.

Kwon, O. N., Park, J. H., \& Park, J. S. (2006). Cultivating divergent thinking in mathematics through an open-ended approach. Asia Pacific Education Review, 7(1), 51-61.

Leung, L. (2015). Validity, reliability, and generalizability in qualitative research. Journal of Family Medicine and Primary Care, 4(3), 324-327. Retrieved from http:// doi.org/10.4103/2249-4863.161306

Martin, A. M., \& Hand, B. (2009). Factors affecting the implementation of argument in the elementary science classroom. A longitudinal case study. Research in Science Education, 39(1), 17-38.

Martino, A. M., \& Maher, C. A. (1999). Teacher questioning to promote justification and generalization in mathematics: What research practice has taught us. The Journal of Mathematical Behavior, 18(1), 5378.

Muir, T. (2009). Investigating teachers' use of questions in the mathematics classroom. In Proceedings of the 33rd Conference of the International Group for the Psychology of Mathematics Education (Vol. 4, pp. 161-168). Thessaloniki, Greece: PME.

Muir, T. (2009). Investigating teachers' use of questions in the mathematics classroom. In International Group for the Psychology of Mathematics Education (Vol. 4, pp. 161-168).

Shahrill, M. (2013). Review of teacher questioning in mathematics classrooms. International Journal of Humanities and Social Science, 3(17), 224-231.

Silver, E. A. (1997). Fostering creativity through instruction rich in mathematical problem solving and problem posing. Zdm, 29(3), 75-80.

Sullivan, P., \& Lilburn, P. (2002). Good questions for math teaching: Why ask them and what to ask. Grades K-6 Math Solutions. Math Solutions Publications: US.

Yee, F. P. (2002). Using short open-ended mathematics questions to promote thinking and understanding. Retrieved from http://math.unipa.it/ grim/SiFoong. PDF 


\section{Appendix A}

\section{Observation Results}

Tuesday, 28 March, Grade 3, Time: 11.00-12.00

$\mathrm{T}=$ teacher

$\mathrm{S}=$ student, 25 children

Red: Open-ended

Purple: Closed

$\mathrm{T}$ : If the answer is 42 what could the question be?

One add, one take away, one times, one divide

$\mathrm{T}$ : Oke I will give you one more minute

Let your mathematics brain working

T: Oke, five, four, three, two, one.

$\mathrm{T}$ : who can give me?

T: oke, Cleo?

C: $40+2=42$

$\mathrm{T}$ : is it correct?

$\mathrm{S}$ : yes

T: Maybe easy, but it's correct

T:oke, Joe?

J: 62 take away $20=42$

$\mathrm{T}$ : is it correct?

$\mathrm{S}$ : Yes

T: oke, Amel?

A: 59 take away (-) 7= 42

$\mathrm{T}$ : ya, amely?

A: $(4.10)+2$

$\mathrm{T}$ : Well done

T: oke, Joe?

J: $32+10$

$\mathrm{T}:$ Sienna?

S: $8 \times 4$

T: Can you tell me what $8 \times 4$ is?

$\mathrm{T}$ : Rovie?

R: 32 , then $+10=42$

T: good, Obsa?

S: $42+0$

T: wow, 42 add nothing equal 42

T: oke, Tom?

Tom: $6 \times 7$

T: oke, $6 \times 7=42$. What's the opposite/ the inverse $6 \times 7$ ?

Cloe: have the same answer

$\mathrm{T}: \mathrm{So}$ ?

C: $7 \times 6$

T: Brian?

B: 42 divided by 1

T: Oh, I like it, so, if 42 divide to one person $=42$

Sienna?

S: $84: 2=42$

$\mathrm{T}$ : SO, what you can see from 42: $1=42$ and $84: 2=42$ ?

$\mathrm{S}$ : talking mathematically, what can you see from between these two?. Amelie, what do you see?

A: if you put 4: $2=2$ and $8: 2=4$

T: yach, you're right, but it's not what I'm seeing here. if you put 4: $2=2$ and 8: $2=4$, but there is something interesting here?

S: it's maybe $42+42=84$ and $1+1=2$

T: yach, think mathematically. Think what's word could I say that? This number (84) is something this number (42) and

This number (2) is something this number (1). Goerge?

G: double two

T: What's double two? Think whole thing

S: 42 double $=82$

T: correct, if you double 42 you get 84 . SO 1 double is...

S: 2

T: So, here we go! If I am take four doble is 82 double is 4 , one double is 2 . So what number if I put here .....: 4 ? If two double is 4 , so double 84 ?

T: what's double 4?

S: 8

T: what's double 8?

S: 16

T: so, 168: 4 . So how if $2 \times 80$ ?

S: we add zero to 16 ? 
T: No, zero doesn't add meaning. So $2 \times 80$ ?

S: $0 \times 2$

T: So?

S: 130

$\mathrm{T}$ : where is come from?

$\mathrm{S}:$ is that 160 ?

T: who is think it is 160 ?

T: so, what's we are doing yesterday?

T: what's an angle? Think about it, Write an answer on your whiteboard... Can you remember the little sentence we said yesterday?

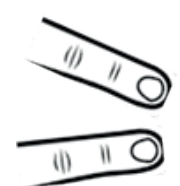

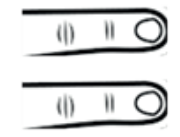

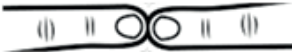

3

T: I have a picture. So you can help me!

S: Show their whiteboard!

T: let's say together!

S: An angle is the amount of turning (1), between two lines (2), that are joined (3)

$\mathrm{T}$ : Show me an angle with your body?

S:

T: Interesting anybody

$\mathrm{T}$ : show me smaller one

S:

T: Larger one

$\mathrm{S}:$

T: Now, using your arm, show me a small angle

S:

T: a bigger angle

S:

T: a slightly bigger angle

S:

$\mathrm{T}$ : show me really really acute angle

S:

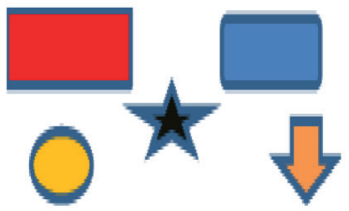

$\mathrm{T}:$

T: Here I have some shapes

$\mathrm{T}$ : What is this (red)?

S: Rectangle

$\mathrm{T}$ : What is this (blue)?

S: square

T: It's not square. Is it?

S: a curved rectangle

T: I like the idea, but we don't have a curved rectangle because rectangle has a watch.

What's rectangle has?

S: straight angles, ages!

$\mathrm{T}$ : is that straight ages?

S: Sharp points up

T: rectangle has a sharp point. Can anybody tell me about the sharp point?

S: doesn't has any corner

T: try again?

S: Angle?

T: yes,

T: What's this (black)?

S: Star

T: does star have an angle?

S: yes

S: No

T: why? To your partner explain why? (discussion)

S: it has sharp point

T: think about sharp thing and straight line, Is there straight line here?

$\mathrm{S}$ : there are two straight line

$\mathrm{T}$ : There are two lines turning and joined. So, is it angle? 
S: yes

T: How about this?

$\mathrm{S}$ : yes

$\mathrm{T}$ : Is this has angle (brown)?

S: yes

T: how's about in the middle?

$\mathrm{S}$ : there is no line in the middle

T: perfect!

T: with your partner, discuss 3 statements about this picture!

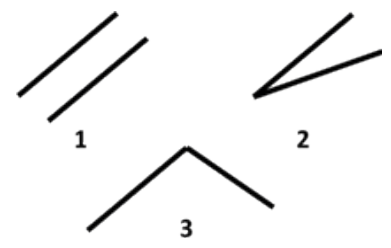

S: It is not an angle (1)

T: why?

$\mathrm{S}$ : it's not joined

$\mathrm{T}$ : others?

S: Angle because that's joined

$\mathrm{T}$ : How do they join?

$\mathrm{S}$ : two lines joined together

$\mathrm{T}$ : Tell me something else about (3)

S: 3 joined, larger than 2 and 2 smaller than 3

T: What's larger? What's smaller?

S: 3 larger, 2 smaller

T: Do you agree?

S: yes

T: what's else about 3 ?

$\mathrm{S}$ : Obtuse angle

T: why?

S: Large

T: Why large? Think about degree

S: More than 900

T: What's 2?

S: Acute angle

$\mathrm{T}$ : What is that?

S: Smaller than obtuse

S: less than 900

T: what's else?

$\mathrm{S}:$ two arms in picture two longer than 3

$\mathrm{T}:$ is it influence angle?

S: No

T: It doesn't matter about the length of arms 


\section{Appendix B}

\section{The Transcript of The Teacher's Interview}

1. What do you think about the role of questions in your teaching?

It depends on actual mathematics that I teach. Do more investigations, if the subject needs questions I will give questions.

Sometimes I will give them task. If I want to make children think deeper than normally they can do,, I will use open questions. While close questions you just want to know the answer. I just push them further by asking open questions.

2. Do you develop another question from students' answer?

Yah...you have to work with them rather than closing the questions because there is an opportunity to develop further with open questions. Sometimes what you plan doesn't go to that way because sometimes it just link to deeper understanding.

3. What do you do to an unexpected answer from students?

Reword the questions, so they understand the questions,. Then, give more a clue, where the question can go, push the teaching somewhere.

4. What is type of question do you prefer asking? Closed or open-ended? Why?

Sometimes, it depends on the subjects. If you want yes or no answer you use closed. If you want a deeper understanding use open-ended because they can make them think and come up with different ideas, and extend the learning, and the time you want to go. Questions Yes or no is clearer. So, I like to think I do both. More open especially in math because you want to see link and the conception rather than think just enough. Push them to inquire what's going on rather than yes or no because they do not learn if it's yes or no.

5. What sources do you use for creating questions?

I have questions in my head based on my learning objective in my plan, but in learning process may be will change depends on students' answer (spontaneous questions)

6. Do you like give oral or written task? Why?

Both, if I am doing teaching input orally maybe the questions come orally. I set them to work by giving them a task to do further

On Tuesday, I think you don't need to have worksheet every single lesson so it just comes from me, while another day, they might have a list of questions about clocks. I don't' need worksheet all the time.

7. What do you do if the child answers your question incorrectly?

I don't' believe there is an incorrect answer. I believe there are just misconceptions. So, I would work with child's response and try to get them by asking them, make students realise about their mistakes rather than say no, that's wrong because it doesn't make a safe environment. They will never hand up to answer. If I say, it's an interesting answer, but let's we look at that and talk about it. So, the whole class will talk about it and I will get to the right answer from that way. We use that wrong as a learning point. We never ever say "No, that's wrong" because it makes students feel terrible. They will never speak questions. Good questions allow for mistakes and you build more questions from that. 


\section{Appendix C}

\section{GSoE Research Ethiscs Form}

\section{Researcher access/ exit}

Every school has privacy to become a research place so that it will be hard to take example directly at school. Therefore, the researcher will receive a help from a lecturer, Laurinda Brown, in finding an access to school. The participants will be taken from a primary school in UK. The target sample group will be a teacher who is teaching mathematics in primary school and the students in his classroom. Although the school will be chosen by Laurinda, there will be discussion about research's purpose in order to find an appropriate school and teacher.

\section{Information given to participants}

Information sheet will be given to participants with a briefing of the project which explain some information related to what the study about is, who will be participated, what participant will do, how information will be recorded, stored and protected as well as the contact information of the researcher for any complains or the researchers themselves for further details about the study.

\section{Participants right of withdrawal}

Participants will be informed about their right of withdrawal in the project through both information sheet and verbally before starting interview. They could withdraw freely at any time up to seven days from the interview taking place without giving any reason and without their rights being affected in any way.

\section{Informed consent}

Besides getting information sheet, participants will be given a consent form about filming and interviewing process to ensure that they agree that they are fully informed before participating in this research. They will consider some points before deciding to engage, that are their consent to become volunteer, to be videotaped and recorded, and used as anonymous quotes in written project report.

\section{Complaints procedure}

Participants are still able to express any complaint by contacting the researcher using email provided in the participant information sheet

\section{Safety and well-being of participants/ researchers}

The researcher will conduct a research in a primary school by filming a whole learning activity without disturbing the learning process (taking children's face is not allowed, so I will observe using observation sheet and sound recording). Then, the interview will be conducted in a place which is agreed by both participant and researcher. The exact location for each interview will be decided further in a way that the participants will feel comfortable in providing the information. Moreover, the participants' voice will be audio recorded, and stored safely.

\section{Anonymity/ confidentiality}

Due to our nature method that is face to face interview, anonymity of the participants is not completely possible. However, confidentiality will be maintained and participant's details not reported. Interview will be recorded on devices that will be kept safe accessed only by the researcher.

The audio files will be transcribed to documents, and used as anonymous quotes in written project report.

\section{Data Collection}

Data will be collected by using videotape for observation and interviewer's note taking as well as the recording of the interview.

\section{Data Analysis}

The videotape of observation will be clarified through interview, but the researchers will not be able to give the transcription of the interview to the participants (to check the accuracy of data) before using the data due to the limited time. However, the researchers will ensure the accuracy of transcription by listening to participants' answer from audio recorder.

\section{Data Storage}

The videotape as well as the recording and transcript of the interview will be stored in researchers' drives locked by password.

\section{Data Protection Act}


The research will follow the Data Protection Act 1998, in that the data will not be shared, stored safely and used only for the purposes as described here.

12. Feedback

In case there is a complaint or a request from the participants about the summary or finding of the research, the researchers give the freedom to participants to contact email provided in the participant information sheet.

13. Response to colleagues/ academic community

The research has been planned with consideration of the rights of the participants, and will be carried out following ethical procedures and approaches discussed within. Researchers are committed to maintain the reputation of the Graduate School of Education and the University of Bristol and will avoid fabrication and misrepresentation of the data and results.

\section{Reporting of Research}

Participant will be informed that this research is the project of one of units taken as Graduate School Education Master Student.

Signed: $x x x x x x x x x$ (Researcher)

Date: 19 February 2017

Signed: xxxxxx (Discussant)

Date: 19 February 2017 


\section{Appendix D}

\section{Participant Information Sheet}

An analysis of a teacher's questioning related to students' responses and mathematical creativity in an elementary school in the UK

I would like to invite you to take part in research study. Before you decide you need to understand why the research is being done and what it would involve for you. Please take time to read the following information carefully. Ask question if anything you read is not clear or if you would like more information. Take time to decide whether or not to take part. What this study is about?

The aim of this research is to describe a teacher's questioning activity related to students' responses and mathematical creativity.

What will taking part involve?

If you agree to take part for this research, you will be asked some questions about your questioning in the classroom regarding the type of questions and questioning strategies. We will ask you to answer the questions based on your questioning activity as a mathematics teacher. The interview will spend about 30 minutes and will be recorded.

Why have you been invited to take part?

We would like to invite you as participant because you are a mathematics teacher.

Do you have to take part?

Taking part in this research is voluntary and you have right whether you agree or disagree to become participant. Then, if you later decide to withdraw from the research after agreeing to involve then you are free to do so at any time up to seven days from the interview taking place without giving any reason and without your rights being affected in any way. What are possible risks and benefits of taking part?

There will be no possible risk for you in this project but we will obtain the description about British mathematics teachers' questioning activity which likely enriches my insight and experience as future mathematics teachers.

How will information you provide be recorded, stored and protected?

Original audio recording will be stored safely. In addition, the transcript of interview will be revealed in my research report.

Who should you contact for complaints and further information?

If you want to ask about further information about this study, please contact Mela Aziza at ma16922@my.bristol.ac.uk 


\section{Appendix E}

\section{Consent Form}

To be completed by the teacher

An analysis of a teacher's questioning related to students' responses and mathematical creativity in an elementary school in the UK

Please answer the following questions to the best of your knowledge (delete as appropriate):

I confirm that I have read and understood the accompanying participant information sheet

Yes/No

I agree to take part in this study Yes/No

I understand that my name or the schools name will not be used in any report Yes/No

I agree that data gathered in this study will be stored anonymously and securely Yes/No

I understand that all personal information will remain confidential Yes/No

Name

Signature

Date _ _ _ _ - - -

Researcher Name

Researcher Signature 